\title{
Top Management Team Diversity and Organizational Performance: The Mediating Effect of Strategic Change
}

\author{
Gachugu Ehud M., PhD. Student \\ School of Business - University of Nairobi, Kenya \\ Prof. Z.B Awino, Associate Professor \\ Dr. Machuki Vincent, Lecturer \\ Dr. X.N Iraki, Lecturer \\ Department of Business Administration, \\ School of Business - University of Nairobi, Kenya
}

Doi:10.19044/esj.2019.v15n13p426 URL:http://dx.doi.org/10.19044/esj.2019.v15n13p426

\begin{abstract}
Organization ability to anticipate and respond to the existing opportunities while observing the need for change is a vital ingredient in sustaining competitiveness and viability. The contemporary organization is faced with shifting competitive and dynamic operating environment requiring regular shifts in strategy by TMT in order to enhance performance. Despite wide interest from scholars, the association between TMT diversity and strategic change and how this influence performance is unclear. This study sought to examine the influence of TMT diversity on performance of Public Benefit Organizations (PBOs) in Kenya and the intervening effect of strategic change. The study relied on the resource based view and upper echelons theories to offer the foundations of the assessment. A cross sectional research design within a positivistic framework was adopted for the study. A sample of 138 respondents was acquired from National and International PBOs. Quantitative and qualitative data collected was analyzed using descriptive and inferential statistics. It was found that TMT Diversity statistically significantly explains $10.4 \%$ of the variability in PBO Performance. Further findings were that TMT diversity only explains $2.8 \%$ of the variability in Strategic Change (an effect confirmed to lack statistical significance); but when strategic change and TMT diversity were considered in a joint effect, the model was found to explain $11.5 \%$ of the variability in PBO Performance. However, the lack of statistical significance in the relationship between strategic change and TMT diversity disproved the mediating role of strategic change in the TMT Diversity and PBO performance relationship. The study therefore concludes
\end{abstract}


that TMT diversity has an influence on PBO performance, though strategic change has no mediating effect in this relationship. The study recommends that the stakeholders in the sector should enhance TMT diversity in their organizations while carefully balancing the role of TMT in driving strategic change. Further studies targeting TMT diversity and strategic change in varying environments and contexts should be undertaken. The study contributes to the upper echelons theory in clarifying the impact of strategic change in TMT diversity and organization performance relationship. It further contributes to the advancement of PBO management policies and practices raising the need to consider instances where TMT diversity can drive or stifle strategic change efforts.

Keywords: Strategic Change, TMT diversity, PBO Performance, intervening effect, Public Benefit Organizations

\section{Introduction}

Globalization has led to increased mobility of labor, consequently causing the need for contemporary institutions to embrace workplace diversity. TMT is one of the most notable areas that diversity is embraced. TMT diversity concept is of essence as it exemplifies the perceptions of how business units or organizations respond to occurrences within their environment. Rosado (2006) posits that organizations are defined by what their leaders think, feel, perceive, and believe hence the level of TMT diversity is an indication of the variances in thought, perception and beliefs within an organization. TMT diversity is important in providing strategic leadership and strategic change to enhance organizational outcomes (Lord et al., 2016). Faced with the uncertainty and scarcity of information that accompanies strategy making dynamic and complex operating environments the role of TMT diversity in driving strategic change becomes essential (Kochan, et al, 2003; Ogundele, 2005; Alina, et al., 2010; Wasike, 2016).

Diversity and inclusion are increasingly becoming strategic organizational accelerators with direct effect on the effectiveness of the organization, reputation, and profitability. The key goal for advocating for diversity and inclusion in Public Benefit Organizations (PBOs) are increasing employee engagement, serving beneficiaries more effectively, and increasing agility and organizational innovation. The question of how these organizations are managed and adopt strategic management practices are issues of great concern. Therefore, there is need to explore the influence of TMT diversity on performance of PBOs as influenced by strategic change.

Globally, PBOs are of great value in the provision of educational, health, social, and environmental services. PBOs are a fundamental contributor to America's economy proving 5.4\% of the countries' total GDP 
and $\$ 887.3$ billion to the U.S. economy in 2012. In 2012, the PBO sector significantly contributed to the country's private sector workforce by providing 11.4 million jobs. This accounted to $10.3 \%$ of the total workforce in the sector (Davies 2014). In Kenya, the PBO sector contributes more than $\$ 1.2$ billion into the country economy annually, with 1.8 percent of the PBOs delivering 45 percent of Kenyan public health services (Kenya Public Health Report, 2014). Therefore, given their social and economic importance, understanding the TMT in these organizations and the strategic management practices they adopt are issues of great importance.

The upper echelons theory argues that the organizations' corporate and business strategy depicts their TMT (Hambrick and Mason, 1984). The same theory opines that the level of diversity within the TMT will determine the capability of the created corporate and business strategies to improve and sustain organization performance (Handika \& Wibowo, 2018). The assessment of the link between the diversity of TMT, strategic change and firm performance is the drive for this study.

\section{Literature Review and Conceptual Hypothesis}

The theories used are given weight based on their relevance and applicability in a TMT diversity discourse and the proposed use in management related issues, and consequently representing the constructs used in the conceptual framework. The force behind sustenance of TMT diversity is the strategic management concept, which is best represented in the upper echelons and strategic leadership theories which espouses the leadership design decisions within the organization (Jensen and Meckling, 1976; Hayes 2016). Another key theory applied in this study is the Resource Based View (RBV) by Wernerfelt (1984). RBV argues that organizations possess tangible and non- tangible resources. This benefit can be sustained over a long time frame to the point that the organization is able to shield against transfer or substitution, resource limitation, making the organization free of resource constraints (Frawley \& Fahy, 2006; Wasike, 2016).

Upper Echelons Theory: The upper echelon theory has been adopted in many studies (such as Knight et al., 1999; Pitcher \& Smith, 2000; Geletkanycz, 1997; Carpenter, 2002; Pegels, Yang \& Song, 2000; Derda \& Dea Flores, 2017; de Kok et al,. 2018). According to Hambrick and Mason (1984), top managers believe that there exists a strong correlation between strategic decision-making and organizational performance. de Kok et al,. (2018) argues that in order to maintain proper organizational operations, efforts of the entire team are required and not just individual effort. Scholars in the Strategy field have advanced Hambrick and Mason's (1984) upper echelons view to opine that since demographic characteristics act as valid indices for inner attributes, then the relative heterogeneity of the prior 
attributes among team members could be linked to organization performance (Hambrick \& Finkelstein, 1987; West \& Schwenk 1996).

The theory is founded within the 'dominant coalition' concept suggesting that idiosyncratic processes, social biases and filters at top of the organization have substantive impact on the competitive behaviours (Hayes, 2016). Hambrick (1994), observed that these competitive behaviours are expected to influence the organization's performance. The seminal paper on Upper Echelon Model by Mason and Hambrick (1984), submitted that TMT characteristics affect the decision making process and thus organization performance. A key Upper Echelon Theory fundamental is that the TMT characteristics have a linkage to the cognitive and psychological components of the administrative orientation, which consequently influence the strategic choices and decisions (Carson et al., 2004; Derda \& Dea Flores, 2017; de Kok et al., 2018).

The upper echelons theory also states that the decisions made by executives are in line with their orientation or cognitive base which constitutes psychological characteristics and observable experiences (Hambrick and Mason, 1984). Upper echelons advocates for measurement of executive orientation through use of discernible demographic characteristics (Derda \& Dea Flores, 2017). Hayes (2016) dubbed this the most relevant theory in TMT diversity research. The theory is significant to this study as it clearly brings forth the importance of TMT diversity and the required abilities in order to curb challenges within the organization and facilitate growth and hence offers a link between TMT diversity and performance.

Resource Based View: Resource based view theory proposed by Wernerfelt (1984) consider an organization as a bundle of resources which enable organizations to realize competitive advantage and gain superior long term performance (Barney, 1991; Wernerfelt, 1984). Resource based theory opines that organizations possess tangible and non- tangible resources that are essential in competitiveness and performance (Balashova \& Gromova, 2016). The organization could leverage on this advantage over a long time span to the extent that it is able to shield itself against resource limitation, substitution or transfer making the organization free of resource constraints (Frawley \& Fahy, 2006). Resource based view theorists argue that a TMT with diverse skill set, cultural background, gender, among other demographic and cognitive qualities, act as strategic resources to organization leading to better performance (Ireland \& Hitt, 1999; Balashova \& Gromova, 2016).

Based on the theory proposition that organizations wield control over their operating environment by preserving the necessary resources for survival, TMT (as much as it is itself a resource) is the bond between the organization and the needed vital resources from the macro environment. Therefore, TMT diversity aids in acquisition of access to critical resources for 
organization success (Hambrick, 2007). Subsequently, resources offer power to organizations where the ease of access to resources is the key determinant of organizational functioning, performance and ultimate survival (Balashova \& Gromova, 2016).

When high discretion is prevailing, then team diversity's role will be integrated into strategy. Discretion exists when there is an absence of constraint. Within an organization setting, the key constraint is the organization's resources (Hambrick, 2007). This theory therefore is a basis for TMT diversity in that the diversity is only impactful when there is discretion which comes from presence of unconstrained resources within the organization (Wasike, 2016). The relevance of this theory to the study is to explain how the resources at an organization's disposal are a fundamental factor to be considered before strategy implementation, environmental scanning or reviewing the top management team and its leadership.

Top Management Team (TMT) embodies the inner circle of executives who jointly formulate, articulate and execute the organization's strategic and tactical moves (Nelson and Nelson, 2012). The organizational levels of both TMT and middle managers influence formulation and implementation of strategies (Wooldridge, et al., 2008; Derda \& Dea Flores, 2017). Diversity is described as division of personal attributes among members of a group (Jackson, et al., 2003). According to Simons, et al., (1999), TMT diversity is the extent degree to which differences exist on background, demographic and functional dimensions in TMT composition. TMT diversity is identified as the variances in qualities that members of top management team can be able to identify their differences with each other, (Mutuku, et al., 2013). TMT diversity introduces human social biases, idiosyncratic processes and filters at the helm of an organization which significantly influences the competitive behaviors likely to influence organization performance (Carson et al., 2004; Derda \& Dea Flores, 2017).

Research on TMT diversity has examined different forms of diversity such as differences in age, gender, nationality, education, organization tenure, and technical and functional background (Jackson, et al., 2003; Hayes, 2016). Though linked to positive impact on the organization, some studies found TMT age and tenure diversity to have negative impacts on group cohesion, frequency of communication, increased political activity and increased conflict within the group and (Eisenhardt \& Schoonhoven, 1990). Ultimately, both negative and positive effects of TMT diversity provide an internal environment with implications on organizational performance (Wasike, 2016; Derda \& Dea Flores, 2017).

Strategic change entails restructuring of the marketing plan of the organization so as attain an important objective (Brown, 2005). Strategic change within an organization involves shifts in its corporate policies, its 
mission, its target market, and its organizational structure. Organization ability to foresee and respond to the existing opportunities while observing the need for change is a vital ingredient in sustaining competitiveness and viability (Zhang \& Rajagopalan, 2010). It is a fundamental way of to maintain proper alignments with shifting demand, competitive, social and technological environments. The nature and effectiveness of organizational responses are dictated by the manner in which TMT triggers strategic issues (Chemengich, 2013; Wasike, 2016). Strategic change strives to improve the competitive position of the company by improving particular elements such as its differentiation and cost position from the competitors (Dess, et al., 2005). Strategic change entails restructuring of activities of the organisation in order to achieve important objectives (Handika \& Wibowo, 2018). It includes shifts in a corporation's target market, policies mission or organizational structure that can generate expected performance gain or unexpected loss (Brown, 2005; Handika \& Wibowo, 2018). TMT is intensively involved in strategic change management, either directly (change in management) or as managers of the change (overseeing the implementation of the change strategy) (Wasike, 2016).

The true nature of strategic decision making is ambiguous, unstructured and complex which makes the interpretations and perceptions of a TMT's member critically influence strategic decisions (Ireland \& Hitt, 1999). The cognitive resource view and the upper-echelons theory describe TMT as one with diverse cognitive resources, more extensive macro contacts and wider vision than the homogeneous team (Chemengich, 2013). However, due to its diversity, internal conflicts might be experienced by the heterogeneous team which hampers the speed of making decisions on matters related to strategic change (Brown, 2005; Handika \& Wibowo, 2018). Literature also indicates that high diversity teams increase the chances of identifying new strategic opportunities and new environmental changes (Alexiev et al., 2010; Derda \& Dea Flores, 2017). Similarly, due to its complexity, new insights, knowledge and resources are required for strategic change diverse cognitive resources and knowledge can be pooled by heterogeneous teams thus develop strategic alternatives within the dynamic environment (Galunic \& Rodan, 2004). Receptivity to change implies openness to pursue various business approaches, necessary for forward minded organizations, hence managing strategic change is a complex and demanding task and requires a fully functional TMT with capable leadership to implement, so as to achieve intended objectives (Jansen, et al., 2009).

Organizational performance encompasses the actual outputs or results realized by an organization, measured against the intended outputs, mainly considered as objectives and goals or the previous period performance (Hailey, 2006). Views posited by Richard et al., (2009) depict organizational 
performance as to comprise of three specific parts of organization outcomes that include product market performance, financial performance and shareholder return. Organizational performance is also defined as a set of financial and non-financial indicators that offer information on the degree of attainment of the organization objectives (Lebans \& Euske, 2006; Jaleha \& Machuki, 2018).

Most organizations measure their performance based on the effectiveness of achieving company goals, while another significant majority views it in terms of efficiency in deploying resources (MacPherson \& Pabari, 2004; Derda \& Dea Flores, 2017). Organizations' superior performance results from its strategic choice that provides a better positioning in the industry structure (Rivkin, 2001). High organizational performance is realized when all fragments of an organization work in unison to attain great results, which are measured based on the value delivered to customers. Some of these parts include the resources, structure, leadership, human resources, business process, and strategy among others (Jaleha \& Machuki, 2018; Handika \& Wibowo, 2018). Productivity, employee turnover, profitability and market share are some of the determinants of an organization performance (Glunk \& Heijltjes, 2009). The TMT performance measures needs to strike a balance in presentation of both the operational and financial measures, hence, the Kaplan and Norton (1992) BSC, which stipulates the measures that provide the TMT with an appropriate outlook of the business, is most preferred (Mutuku, et al., 2013).

Public Benefit Organizations (PBOs) link a larger portion of their organizational performance to the results of their programs which are designed in view of improving the lives of the targeted group rather than the financial gains acquired within the organization. Their performance is all about meeting or exceeding stakeholders' needs and expectations (Hailey, 2006) and therefore mission driven. Just like private sector, PBOs are expected to enhance these performance facets in order to remain relevant and improve their performance to ensure attainment of their mission in a sustainable manner. The performance measures widely utilized in PBOs is the Balanced Score Card (BSC) applying financial and non-financial measures, which allow managers to perceive the organization from four key perspectives which are: innovation and learning, customer, financial perspectives and internal business (Horvath \& Seiter, 2009). Financial performance in PBOs are mainly measured in three dimensions of financial sustainability, efficiency and effectiveness. The non-financial (operational) organization performance measures involve optimization of all the required inputs such as human resources that make sure activities are carried out, and other stakeholders such as beneficiaries and partners (Lewis, 2009). Such an integrated view would offers a comprehensive link between all performance aspects of PBO (Epstein 
\& McFarlan, 2011). Organization performance in this study is therefore measured by the combination of both financial and non-financial measures within the extended balanced scorecard framework.

In Kenya, Public Benefit Organization is described as a private voluntary association of persons or associations operated for nonprofit reasons or other commercial endeavors but which have grouped themselves nationally or internationally for public health and promotion of social welfare, charity, development or research in other fields such as education, agriculture, industry and procurement (PBO Act, 2013; under Section 5-2). PBOs in Kenya play a fundamental role in social and economic development especially in job creation and provision of social services. The PBO sector comprises of 8,569 organizations, employs more than 250,000 Kenyans, with an annual budget of over Kshs. 80 billion per year and directly offer essential services to many Kenyans (PBO coordination Board, 2014). They are actively involved in other sectors such as agriculture, education, water, health, environment, gender and development, human rights, poverty alleviation, children's rights, population, peace, counselling, training, disability and small scale enterprises among others (Dekings, 2015). Most PBOs are administered by volunteers within the communities but are rooted locally, and are neither for sale nor focused on profit maximization for shareholders. They invest in and enrich the local communities in the long term, thus helps revive the local economies, rather than enriching a few individuals.

The management of PBOs is different from that of other corporations and is known to be highly dynamic. Due to their role, the way PBOs are managed and led is of great importance. Public benefit organizations management operate their organizations with similar authority as that of a traditional corporation, with a focus of achieving their mission and not profitability. The nature and accuracy of PBO's performance vary depending how strategic issues are triggered and interpreted by the top management (Lord et al., 2016). Wiersema et al., (1992), posits that the characteristics of a top management team anticipated to be able to initiate strategic change include willingness to risk, receptivity to change, information sources diversity and perspectives, and creativity and innovativeness hence influence performance. Yong et al., (2011) argue that the diversity of TMT demography significantly influence strategic change. However, though other studies speculate that diversity could be a source of explorative undertakings such as strategic change, others suggesting that diversity could cause difficult integration, thus negatively influencing strategic change (Kim \& McIntosh, 2011; Handika \& Wibowo, 2018).

Organizations which embark on strategic changes have TMT whose traits present their receptiveness to change and inclination to take risks (Zhang \& Rajagopalan, 2010). Further, the demographic heterogeneity cites diversity 
for the information perspectives and sources, innovativeness and creativity in decision making (Handika \& Wibowo, 2018). It is important for strategic change agents who in most case are leaders, to critically analyze their strategic content to be able to achieve planned level of performance (Derda \& Dea Flores, 2017). Based on these facts, we suggested that strategic change mediates the association between TMT diversity and organization performance, which was tested by empirical analysis of specific aspects of that general relationship. This above discourse therefore leads to the following conceptual hypothesis:

$\left(\mathbf{H}_{\mathbf{a} 1)}\right.$ : Strategic Change has a mediating influence on the relationship between Top Management Team Diversity and Organizational Performance of PBOs in Kenya.

\section{Methods}

The study targeted all national and international PBOs operating in Kenya estimated to be 8,569 (NGO Coordination Board of Kenya, 2014). Through the application of Cochran (1963) sample size determination equation $\left(\mathrm{n}_{\mathrm{o}}=\frac{\boldsymbol{z}^{2} \boldsymbol{p q}}{\boldsymbol{e}^{2}}\right)$, the study realized a representative sample of 138

PBOs in Kenya for the study. Stratified Random Sampling was applied to select PBOs along the key sectors of operation such as Agriculture, Health, Children and Youth development, Education, training and Skills Development, and Environment \& Economic Empowerment. The study relied on both secondary and primary data which was in qualitative and quantitative format. Semi - structured questionnaire were used to collect primary data which were supplemented using secondary data collected from Annual reports and organizations websites. The questionnaires were administered by the researcher assisted by a research assistant to the select study respondents within PBOs through drop and pick method. The respondents included the Human Resource managers or equivalent who reports directly to the Chief Executive officer. Alternatively, where available, the study acquired data from Directors, CEO or the General Managers.

\section{Findings}

The study sought to understand the intervening influence of strategic change (SC) on the relationship between TMT Diversity and PBOs performance. This was achieved using an OLS regression model which tested for the intervening effect. So as to assess the intervening effect using a regression model, the researcher has to confirm that the independent variable has an effect on the dependent variable, the independent variable has an impact on the intervening variable and the intervening variable has impact on the dependent variable if the independent variable is controlled. This was the 
guiding framework of undertaking this assessment. It was achieved by creating three linear regression models within which the mediating effect was assessed. The three regression models included the first model where PBO Performance was regressed against TMT Diversity, the second model was where Strategic Change (intervening variable) was regressed against TMT Diversity (independent variable), while the third model was where PBO performance was regressed against TMT Diversity and Strategic Change.

Table 1 presents the regression models summary, the ANOVA and the Coefficients sections of the ordinary least square (OLS) regression analysis. From the model summary of the regression analysis, Model 1 that regressed TMT Diversity against PBO Performance, was observed to have a positive correlation coefficient $(\mathrm{R}=0.323)$ and a positive coefficient of determination $\left(\mathrm{R}^{2}=0.104\right)$ confirming that TMT Diversity can explain $10.4 \%$ of the variability in PBO Performance and that TMT Diversity positively influences PBO Performance. Model 2 presents the regression between Strategic Change and TMT Diversity. The model 2 summary shows a very low positive correlation coefficient of $(\mathrm{R}=0.167)$ and a very low coefficient of determination $\left(\mathrm{R}^{2}=0.028\right)$ indicating that TMT diversity only explains $2.8 \%$ of the variability in Strategic Change (Negative $\mathrm{R}^{2}$ when adjusted for error) indicating a nearly negligent influence of TMT diversity on Strategic Change. This leaves one with no clarity of the influence of TMT diversity on strategic change as indicated by the coefficient of determination where very low coefficient is realized hence clarity will only be realized from further analysis within the regression model.

Table 1: Strategic Change, TMT Diversity, and PBO Performance Relationship

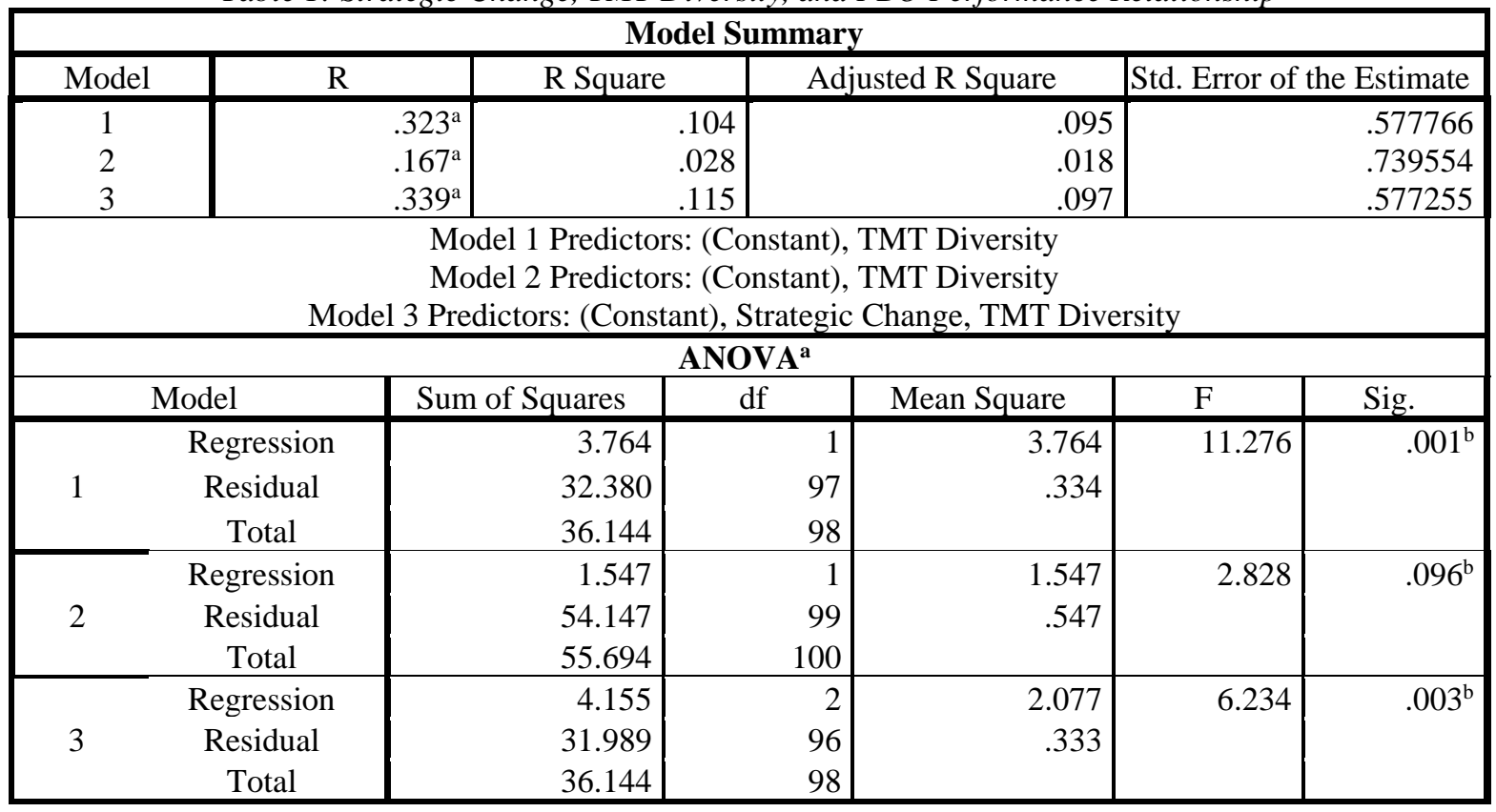




\begin{tabular}{|c|c|c|c|c|c|c|}
\hline \multicolumn{7}{|c|}{$\begin{array}{l}\text { a. Model } 1 \text { Dependent Variable: Organization Performance } \\
\text { Model } 2 \text { Dependent Variable: Strategic Change } \\
\text { Model } 3 \text { Dependent Variable: Organization Performance }\end{array}$} \\
\hline \multicolumn{7}{|c|}{$\begin{array}{l}\text { b. a. Model } 1 \text { Predictors: (Constant), TMT Diversity } \\
\text { b. Model } 2 \text { Predictors: (Constant), TMT Diversity } \\
\text { c. Model } 3 \text { Predictors: (Constant), Strategic Change, TMT Diversity } \\
\end{array}$} \\
\hline \multicolumn{7}{|c|}{$\begin{array}{c}\text { Coefficients }^{\mathrm{a}} \\
\end{array}$} \\
\hline \multirow{2}{*}{\multicolumn{2}{|c|}{ Model }} & Unstandardized & Coefficients & Standardized Coefficients & \multirow[t]{2}{*}{$\mathrm{t}$} & \multirow[t]{2}{*}{ Sig. } \\
\hline & & $\mathrm{B}$ & Std. Error & Beta & & \\
\hline \multirow{2}{*}{1} & (Constant) & 1.105 & .290 & \multirow[b]{2}{*}{.323} & 3.813 & .000 \\
\hline & TMT Diversity & 2.506 & .746 & & 3.358 & .001 \\
\hline \multirow{2}{*}{2} & (Constant) & 3.030 & .367 & \multirow[b]{2}{*}{.167} & 8.262 & .000 \\
\hline & TMT Diversity & 1.590 & .946 & & 1.682 & .096 \\
\hline \multirow{3}{*}{3} & (Constant) & .850 & .374 & \multirow{3}{*}{$\begin{array}{l}.303 \\
.106 \\
\end{array}$} & 2.273 & .025 \\
\hline & TMT Diversity & 2.350 & .759 & & 3.094 & .003 \\
\hline & Strategic Change & .087 & .081 & & 1.082 & .282 \\
\hline \multicolumn{7}{|c|}{$\begin{array}{l}\text { a. Model } 1 \text { Dependent Variable: Organization Performance } \\
\text { b. Model } 2 \text { Dependent Variable: Strategic Change } \\
\text { c. Model } 3 \text { Dependent Variable: Organization Performance }\end{array}$} \\
\hline
\end{tabular}

The regression Model 3 shows the influence of strategic change and TMT diversity on the PBO Performance. The model indicates a higher correlation than in model $1(\mathrm{R}=0.339)$ and consequently a higher coefficient of determination $\left(\mathrm{R}^{2}=0.115\right)$, an indication that when strategic change and TMT diversity joint effect is considered, the model explains $11.5 \%$ of the variability in PBO Performance, an indication that model 3 has a slightly higher ability to explain PBO Performance than model 1.

Further analysis revealed the regression analysis ANOVA model for each of the relationships tested (model 1, 2, \& 3). From the ANOVA analysis, the hypothesis of each of the regression models was sought where model 1 and model 3 were found to be statistically significant (model $1 \mathrm{p}=0.001$; model 3 $\mathrm{p}=0.003$ ). This shows that the association between TMT Diversity and PBO Performance and the association between TMT Diversity, Strategic Change and PBO performance are statistically significant. However, the ANOVA indicated that the second model (model 2 ) was not statistically significant (P $=0.096$ ) at $95 \%$ confidence level hence showing that TMT Diversity influence on Strategic Change, unlike the expectation of the intervening variable model, is not statistically significant. This also confirms the nearly negligible influence observed in the model summary where a very low coefficient of determination $\left(R^{2}=0.018\right)$ was observed. From these findings, the study fails to reject the null hypothesis that Strategic Change has no intervening impact on the association between TMT Diversity and Performance.

Model 1 of the regression models as presented in the coefficients section confirmed that TMT diversity influences PBO performance with a 
positive coefficient and a p-value less than 0.05 (p-value $=0.000)$ indicating that the coefficients are statistically significant and the regression model does confirm the influence. Model 2 regression coefficients confirmed the observation made in the ANOVA analysis of the Model with the coefficient of the relationship between TMT Diversity and Strategic Change being observed to be not statistically significant since the model indicated a p-value greater than 0.05 (P-value $=0.096-$ study fail to reject the null hypothesis, $\mathrm{H}_{\mathrm{o}}$ ), indicating that there is no relationship. Model 3 regression coefficients were on the other side observed to be statistically significant for TMT diversity $(\mathrm{p}=0.000)$ but not significant for strategic change $(\mathrm{p}=0.282)$, an indication of a joint influence which puts to question the value of Strategic Change on the model and its relationship with PBO Performance.

The intervening effect is tested in a regression model by following a four step model in which several regression models and significance of the coefficients are examined at each step, making up the four conditions (Hayes, 2013). The first condition is that there is a direct relationship between independent $(\mathrm{x})$ and dependent $(\mathrm{y})$ variables $\left(\mathrm{Y}=\beta_{\mathrm{o}}+\beta_{1} \mathrm{X}+\mathrm{e}\right)$. The second condition is that there exists the association between independent $(\mathrm{x})$ and mediating $(\mathrm{m})$ variable $\left(\mathrm{M}=\beta_{\mathrm{o}}+\beta_{\mathrm{i}} \mathrm{X}+\mathrm{e}\right)$. The third condition is that there is a link between the dependent $(\mathrm{y})$ and mediator $(\mathrm{m})$ variables $\left(\mathrm{Y}=\beta_{\mathrm{o}}+\beta_{2} \mathrm{X}+\right.$ $\left.\beta_{3} \mathrm{M}+\mathrm{e}\right)$. The fourth condition is that the coefficient in the first condition is higher than the one observed in the third condition $\left(\beta_{1}>\beta_{2}\right)$, which helps in identifying the presence of an indirect effect $\left(\beta_{\text {indirect }}=\beta_{1}-\beta_{2}\right)$.

The first condition for the intervening effect was met when the study found that TMT diversity was observed to influence PBO performance. However, the model failed the second condition of the intervening effect where strategic change was observed to lack a statistically significant effect on TMT diversity. The study however met the third condition of the intervening effect where the independent variable (TMT diversity) and intervening variable (strategic change, though the coefficient was not statistically significant) ought to have a joint effect on the dependent variable (PBO performance). A fourth condition of the intervening relationship is that TMT diversity influence on PBO Performance is higher in model 1 than in model 3, which was met where model 1 coefficient (2.506) was observed to be higher than model 3 coefficient (2.350). The study therefore confirms that strategic change and TMT Diversity have a joint influence on PBO Performance which slightly improves the relationship between TMT Diversity and PBO Performance, hence can be considered as a variable in this model. However, strategic change fails in its ability to have an intervening influence on the relationship given that it fails to meet one of the four conditions of intervening relationship. The study can therefore conclude that Strategic 
Change showed no intervening impact on the association between TMT diversity and organizational Performance.

The research looked at the intervening effect of strategic change on association between TMT diversity and PBO performance by conducting a regression analysis. It was found that strategic change, TMT diversity and Organization Performance have a low positive correlation which is statistically insignificant confirming lack of relationship between the two factors. The study further found that the regression model testing for the intervening effect (with strategic change as intervening variable and TMT diversity as independent variable and PBOP performance as dependent variable) indicated that though the independent variable (TMT diversity) has an impact on dependent variable (PBO performance), TMT diversity has no statistically significant influence on strategic change hence confirming that strategic change has no intervening effect on the relationship between TMT Diversity and PBO Performance. This is unlike the findings of Wiersema et al., (1992), who found that TMT Diversity influences Strategic Change, opining that a TMT is anticipated to be proactive in instigating strategic change including the level of receptiveness to change, inclination towards risk taking behaviours, ensuring diversity in information sources and perspectives, and ensuring there is innovativeness hence influence organizational performance.

The study dispute views by Mekgoe (2008) who claimed that TMT diversity inspired Strategic Change which doesn't have significant impact on staff morale, performance and commitment. However, Frawley and Fahy, (2006) while arguing within the conception of the Upper-echelons theory opines that the impact of team diversity on strategic change is directly influenced by the extent of managerial discretion in the organization, hence the influence is not clear. The study therefore found that strategic change has no intervening influence on the association between TMT Diversity and performance of PBOs.

\section{Conclusion}

The study observed that strategic change practices were moderately integrated among majority of the PBOs studied, among them, periodical strategic plans, creating reforms, guiding decision making, and stakeholders involvement in decision making. Strategic change strategies provides the organization with the capacity to anticipate and respond to the existing pressures for change which is one of the most important ways in which competitiveness and viability are safeguarded (Handika \& Wibowo, 2018). Strategic change is an important way of maintaining proper alignment with shifting demand, and competitive, technological, and social environments (Hayes, 2016; Derda \& Dea Flores, 2017). The study found that strategic 
change has no intervening effect on the association between TMT diversity and PBO performance. This finding conflicts with finding by Wooldridge et al., (2008) who observed that the organizational levels of TMT diversity influence strategy formulation and implementation. However, Chemengich (2013) found that nature and effectiveness of organizational responses vary with respect to how TMT triggers and interprets strategic matters, hence the impact of strategic change to performance rely greatly on the TMT. From these findings, the study concludes that strategic change does not have an intervening influence on the association between TMT diversity and PBO performance.

\section{Implications of the Study}

It was also in the interest of the study to explore the effect of strategic change on the association between TMT diversity and PBO performance. The findings of this study have implications on strategic management theory, policy, practice and methodology.

Theoretical Implications: This study was grounded on various resource based view and theoretical models of upper echelons. The outcomes of the study contribute to reinforcement of the existing body of literature by providing empirical evidence that TMT diversity \& strategic change influence the performance of PBOs in Kenya. The study key finding is that there is no intervening influence of strategic change on the association between TMT Diversity and PBO Performance. The research therefore makes a significant contribution in offering empirical foundation to the upper echelons theory by confirming its hypothesis within the PBO sector that TMT diversity influences organization performance. These results are in line with the postulations of resource based view theory. Therefore, these findings are an empirical evidence and contributions to these theories within the PBO sector in Kenya.

Implications on Policy: The study also has policy implications in terms of decision making within the PBO sector in Kenya. The PBOs plays a key role in the Kenyan economy and its performance is an important agenda for all within the country. This study will assist policy makers to make sound decisions regarding the management of TMT diversity and their role in driving strategic change in an organization. The study found that TMT diversity role in instituting strategic change has a low impact on PBO performance that may be improved through the adoption of better management policies. The results suggest that PBOs should consider strategic change practices within their TMT diversity policies in order to attain a better impact on performance. Policy makers in the sector should therefore encourage the PBOs to take advantage of TMT diversity to improve their performance.

Implications for Methodology: The study applied a cross - sectional research design within a positivistic framework. This method augured well 
with the quantitative and qualitative data collected and ensured the realization of predictive and interpretive outcomes through hypothesis generation and testing. This methodology is therefore appropriate for similar future studies when measuring effect and hence the study proposes this methodology in similar assessments in other contexts. Additionally, the study applied linear regression model to assess the moderating and intervening effects within the models. Many researchers dissuades against usage of linear regression models in assessing the intervening influence with most proposing usage of Structural Equation Modelling (SEM) which is very complex. This study, upon ensuring that the regression models lack any errors within it, the regression analysis was undertaken ending up with reliable outcomes. This confirms that upon ensuring a regression model has no errors, regression can be used to assess the moderating and intervening effects.

\section{References:}

1. Alina V., Belu N., Parpandel D. E., \& Rizea I. E., (2010). The Impact of Macro Environment on Organizational Development Strategy. Constantin Brancoveanu University

2. Balashova E.S \& Gromova E.A., (2016). Resource-based view as a perspective management model in Russian reality. Problems and Perspectives in Management, 14(2-2), 325-330. doi:10.21511/ppm.

3. Barney. J. (1991). Firm resources and sustained competitive advantage. Journal of Management, 17.

4. Brown, S.W. (2005). Opportunities and imperatives for improving marketing thought, practice, and infrastructure. Journal of Marketing, $69,1-25$.

5. Carpenter, M. A., Geletkanycz, M. A., \& Sanders, G. W. (2004). Upper Echelons Research Revisited: Antecedents, Elements, and Consequences of Top Management Team Composition. Journal of Management, 30(6), $749-778$.

6. Chemengich, M. K. (2013). Managing strategic change in public sector. Standard Research Journal of Business Management, 1, 1-40

7. Davies, Thomas (z). PBOs: A New History of Transnational Civil Society. New York: Oxford University Press. p. 3. ISBN 978-0-19938753-3.

8. de Kok, A. G., Grob, C., Laumanns, M., Minner, S., Rambau, J., \& Schade, K. (2018). A typology and literature review on stochastic multi-echelon inventory models. European Journal of Operational Research, 269(3), 955-983. DOI: 10.1016/j.ejor.

9. Dekings M. D. (2015). Strategic Management Practices Adopted by Public Benefit Organizations in Homa Bay County, Kenya. MBA Thesis, University of Nairobi 
10. Derda D. \& Dea Flores D.O.O., (2017). International Experience in Upper Echelon Theory: Literature Review. Business Systems Research, 8(2).

11. Dess, G. G., \& Lumpkin, G. T., \& Taylor, M. L. (2005). Strategic management: Creating Competitive Advantages. 2nd Edition. Burr Ridge, IL: McGraw-Hill.

12. Eisenhardt, K.M. \& Schoonhoven, C.B. (1990). Organizational growth: linking founding team, strategy, environment, and growth among US semiconductor ventures in 1978-1988. Administrative Science Quarterly, 35, 504-29.

13. Epstein, M. J., \& McFarlan, F. W. (2011). Non-profit vs. For-Profit Boards: Critical Differences. Strategic Finance, London.

14. Finkelstein, S. \& Hambrick D.C., (1996). Strategic leadership: Top executives and their effects on organizations. New York: West Publishing Company.

15. Frawley, T. \& Fahy, J., (2006). Revisiting the First-Mover Advantage Theory: A Resource-Based Perspective. Irish Journal of Management, 27 (1), 273- 295.

16. Glunk, U., \& Heijltjes, M. (2009). Performance implications of altering team composition. International Journal of Human Resource Management, 4: 765-783.

17. Hailey, J. (2006). NGO Leadership Development: A Review of Literature. Praxis Paper

18. Hambrick, D. C, \& Finkelstein, S. (1987). Managerial discretion: A bridge between polar views on organizations. In L. L. Cummings \& B. M. Staw (Eds.). Research in organizational behaviour, 9: 369-406. Greenwich, CT: JAI Press.

19. Hambrick, D.C. \& Mason P.A. (1984). Upper echelons: The organization as a reflection of its top managers. Academy of Management Review, 9(2): 193-206.

20. Hambrick, D.C. (1989). Guest editor's introduction: putting top managers back into the strategy picture. Strategic Management Journal, 10, 5-15.

21. Hambrick, D.C., Cho T., \& Chen M. (1996). The influence of top management team heterogeneity on firms' competitive moves. Administrative Science Quarterly, 41

22. Handika R.F. \& Wibowo A., (2018). Top Management Team Diversity, the Strategic Isomorphism and Firms' Performance: A Study in the Indonesian Banking Industry. Academy of Strategic Management Journal, 17(3) 
23. Hayes A.F., (2013). Introduction to mediation, moderation, and conditional process analysis: a regression based approach. New York, Guilford Press

24. Hayes J. (2016). Does CEO Resilience matter? An upper echelons perspective. Business administration. Université Paris-Saclay

25. Horvath, P. \& Seiter M. (2009). Performance Measurement. Die Betriebswirtschaft, 69 (3), 393-413.

26. Ireland, R. D., \& Hitt, M. A. (2005). Achieving and maintaining strategic competitiveness in the 21st century: The role of strategic leadership. Academy of Management Executive, 19(4), 63-77.

27. Jackson, S.E., Joshi, A. \& Erhardt, N.L. (2003). Recent research on team and organizational diversity: SWOT analysis and implications. Journal of Management, 29 (6), 801-830.

28. Jaleha A.A. \& Machuki V.N., (2018). Strategic Leadership and Organizational Performance: A Critical Review of Literature. European Scientific Journal, 14,(35), ISSN: 1857 - 7881

29. Jansen, J., Vera, D., \& Crossan, M. (2009). Strategic leadership and exploratory and exploitative innovation. The Leadership Quarterly, 20 (1), 5-18.

30. Jensen, M. C. \& Zajac, E. J. (2004). Corporate elites and corporate strategy: How demographic preferences and structural position shape the scope of the firm. Strategic Management Journal, 25: 507-24.

31. Kaplan, R.S \& Norton, D.P. (1992). The Balanced Scorecard Measure that Drives Performance. Harvard Business Review

32. Kim, E., \& Mc Intosh, J. C.(2011). The Faster, the Better?: An Empirical Study on the Speed of Strategic Change and Firm Survival and Performance. Journal of Applied Business Research, 12 (2), 35 40

33. Kochan, T., et al., (2003). The effects of diversity on business performance: Report of the diversity research network. Human Resource Management, 42: 3-21.

34. Lewis, T. (2009). Practical Financial Management for PBOs. MaPBO (Management Accounting for NoPBOvernmental Organizations). London.

35. Lord, R. G, Devlin, S. H, Caldwell, C. O, \& Kass, D.(2016).Leadership in the National Football League: Do Leaders Make a Difference? In Leadership Lessons from Compelling Contexts. Monographs in Leadership and Management, 8, 29 - 66

36. MacPherson, H., \& Mine P. (2004). Assessing Organizational Performance. The world Conservation Union Report. London Thompson Learning. 
37. Mekgoe, N. (2008).The impact of strategy change on morale, performance and commitment. MBA Thesis, Durban University of Technology

38. Mutuku. C.M (2012). Factors influencing relationship between Top Management team Diversity and performance of Commercial Banks in Kenya. International Journal of Business and Public Management, 1(4).

39. Ogundele, O.J.K. (2005). Management and Organization: Theory and Behaviour. Sabte Book Series, Lagos, Nigeria

40. Richard, O. C., Murthi, B. P. S., \& Ismail, K. (2007). The impact of racial diversity on intermediate and long-term performance: The moderating role of environmental context. Strategic Management Journal, 28, 1213-1233.

41. Rivkin, J., (2001). Estimating the performance effects of business groups in emerging markets. Strategic Management Journal, 22: 4574.

42. Rosado, C. (2006). What Do We Mean By "Managing Diversity"? ICAFAI University, 3. Sumati Reddy, Hyderabad, India

43. Simons, T., Pelled, L.H. \& Smith, K.A. (1999). Making use of difference: diversity, debate, and decision comprehensiveness in top management teams. Academy of Management Journal, 42, 662-73.

44. Wasike S. (2016). Top Management Team Characteristics, Strategy Implementation, Competitive Environment and Organizational Performance: A Critical Review of Literature. International Journal of Economics, Commerce and Management, 4 (6), ISSN 23480386

45. Wernerfelt, B. (1984). A resource-based view of the firm. Strategic Management Journal. 5: 171-180

46. West, C.T. Jr. \& Schwenk C.R., (1996). Top management team strategic consensus, demographic homogeneity and firm performance. Strategic Management Journal, 17(7), 571-576.

47. Wiersema M. F., \& Bantel, K. A. (1992). Top Management team demography and corporate strategic change. Academy of Management Journal, 35, 91-121.

48. Wooldridge, B., Schmid, T. \& Floyd, S.W. (2008). The Middle Management Perspective on Strategy Process: Contributions, Synthesis, and Future Research. Journal of Management, 34(6).

49. Yan, X., (2009). Linear Regression Analysis: Theory and Computing. World Scientific, 1-2

50. Yin, R.K. (2003). Case study research design and methods. Sage publications, 3, Thousand Oaks. 
51. Yong, D. Michel, J. \& Hambrick, D. (2011). Diversification posture and top management team characteristics. Academy of Management Journal, 76, 9-37.

52. Zhang, Y., \& Rajagopalan, N., (2010). Once an Outsider, Always an Outsider? Ceo Origin, Strategic Change, and Firm Performance. Strategic Management Journal, 31 (3), 334-346 